\title{
O efeito mediador das proxies de controle gerencial na relação características do empreendedor e desempenho organizacional
}

\author{
Rosilei de Fátima Martins de Souza Fonseca \\ https://orcid.org/0000-0002-4947-2653 | E-mail: rosilei.martins@yahoo.com \\ Márcia Maria dos Santos Bortolocci Espejo \\ https://orcid.org/0000-0002-9081-781X | E-mail:marcia.bortolocci@ufms.br \\ André Felipe Queiroz \\ https://orcid.org/0000-0001-8395-8035 | E-mail:andre.queiroz@ifms.edu.br
}

\section{Resumo}

Objetivo: A fim de compreender as influências das características do empreendedor sobre o desempenho organizacional financeiro e não financeiro, busca-se, neste estudo, avaliar o efeito mediador das proxies de controle gerencial nessa relação.

Método: A amostra foi composta de piscicultores atendidos por um programa brasileiro de assistência técnica. Os dados foram coletados por meio de questionário aplicado entre outubro e novembro de 2018 e analisados por meio de modelagem de equações estruturais (SEM), com auxílio do software SmartPLS ${ }^{\star}$. Resultados: A mediação das proxies de controle gerencial, na relação estabelecida, ocorre de forma parcial e concorrente. Houve necessidade de reespecificação do modelo inicial, conforme apontamento das análises. O modelo final indicou que características do empreendedor influenciam diretamente, de forma negativa, o desempenho organizacional em $36,4 \%$, enquanto e, por meio das proxies de controle gerencial, o efeito foi positivo em $41,3 \%$.

Contribuições: A presença de características empreendedoras isoladamente não geram tantos efeitos positivos esperados no desempenho organizacional quanto ao combiná-los com o uso de controles gerenciais. Proxies de controle gerencial contribuem, significativamente, para o desempenho de pisciculturas. A pesquisa supre ainda a demanda por estudos de contabilidade gerencial em pequenas organizações e de pesquisas em contabilidade que façam uso do PLS-SEM.

Palavras-chave: Características do empreendedor; Proxies de controle gerencial; Desempenho; Piscicultura; Agronegócio. 


\section{Introdução}

O empreendedorismo enquanto área de investigação científica recebeu maior atenção a partir dos anos 70 (Cooper, 2003), assumindo, desde então, um aspecto multifacetado (Low \& Macmillan, 1988). Considerando que tanto as ações empreendedoras como suas características são importantes para o processo empreendedor (Silva, Gomes \& Correa, 2009), a análise das características pessoais do empreendedor e como elas se inter-relacionam com o desempenho organizacional se mostra uma linha de estudos plausível. Para a melhor compreensão do processo empreendedor e de temas adjacentes, é necessário considerar o empreendedor individual como agente-chave (Obschonka \& Stuetzer, 2017).

A literatura preconiza a existência de variáveis que medeiam a relação empreendedora versus desempenho (Rauch, Wiklund, Lumpkin \& Frese, 2009). Spillecke e Brettell (2013) demonstraram que características empreendedoras, ao serem conectadas ao controle gerencial, apresentam significativa relação com o desempenho. Da mesma forma, Daciê (2016) identificou que a mediação do uso de proxies de controle gerencial potencializou o efeito positivo entre orientação empreendedora e o desempenho das organizações.

Há um contínuo apontamento na literatura de que o controle gerencial atua relevantemente no suporte à gestão das organizações (Otley, 1994; Padoveze, 1999; Frezatti, Carter \& Barroso, 2014). Esta conjuntura estimula o interesse por compreender melhor a relação do controle gerencial com outros fatores que permeiam as organizações e que podem desencadear melhores resultados.

Assim, se de fato o controle gerencial atua positivamente na relação características do empreendedor e desempenho, questiona-se: Qual o efeito mediador da proxies de controle gerencial na relação características do empreendedor e desempenho organizacional das pisciculturas do Estado de Mato Grosso do Sul?

Em relação à população pesquisada, a aquicultura, bem como a piscicultura têm representado um importante setor da economia. Estimativas demonstram que a aquicultura continuará sendo o setor produtivo de alimentos com maior crescimento (IPEA, 2017). No que tange à produção piscícola brasileira, o Estado de Mato Grosso do Sul (MS) aparece em $17^{\circ}$ colocado, com produção bem abaixo dos seus estados vizinhos. Dados apresentados pelo IBGE (2015) expõem a necessidade de desenvolvimento da atividade no Estado de MS, bem como na maioria dos estados brasileiros.

Porquanto, em face da questão de pesquisa, o objetivo geral do estudo consiste em avaliar o efeito mediador das proxies de controle gerencial na relação características do empreendedor e desempenho organizacional das pisciculturas do Estado de Mato Grosso do Sul. A justificativa, para tanto, centra-se em sua contribuição à linha teórica que visa à busca de características empreendedoras relacionadas ao sucesso ou ao desempenho dos empreendimentos, de forma que essas características são apontadas, por vezes, como elementos influenciadores do desempenho (Man, Lau \& Chan, 2002; Mitchelmore \& Rowley, 2010). Do mesmo modo, objetiva também explicitar a atuação das proxies de controle gerencial em uma atividade agronegócio, importante setor da economia brasileira.

Além do mais, investigações sobre a atuação da contabilidade gerencial nas Micro e Pequenas Empresas (MPEs) são demandadas, uma vez que a maioria das pesquisas existentes na área considerou o ambiente de empresas grandes (Mitchell \& Reid, 2000; Ahmad \& Zabri, 2016). Há também uma requisição por pesquisas em contabilidade que façam uso da modelagem de equações estruturais com estimação Partial Leats Squares - PLS/SEM - (Nascimento \& Macedo, 2016). As próximas seções compreendem o referencial teórico, os procedimentos metodológicos, a análise e discussão dos resultados e as considerações finais. 


\section{Referencial Teórico}

O suporte teórico da pesquisa foi realizado por meio levantamento bibliográfico exploratório (primeira fase) e sistemático, por meio do software Start ${ }^{\oplus}$ (segunda fase). Ao final da revisão sistemática, identificaram-se dois artigos que abordam a relação características do empreendedor e desempenho; um artigo que aborda a relação características do empreendedor práticas de controle gerencial; e dois artigos que tratam de práticas de controle gerencial e desempenho - conforme protocolo estipulado. Esses retornos apontam a lacuna de estudos que abordam a relação entre esses construtos. Com base nesses levantamentos, nos tópicos a seguir, são discutidas as relações entre os construtos e expostas as hipóteses da pesquisa.

\subsection{Características do Empreendedor e o Desempenho}

A literatura de empreendedorismo contempla duas principais correntes de investigações: a econômica e a psicológica. Na corrente econômica contemporânea, Joseph Schumpter, um de seus principais autores, configura o empreendedor como agente de inovação, considerando este atributo a base para o desenvolvimento econômico (Fillion, 1999). Na corrente psicológica, David McClleland (1972) argumenta que, além da forma racional implicada nas decisões do homem, há outros fatores de natureza psicológica e sociológica que podem justificar o crescimento econômico.

No esforço por caracterizar o empreendedor, McClelland (1987) - principal autor da corrente psicológica do empreendedorismo - apresentou, no relatório de seu estudo sobre as características do empreendedor de sucesso, uma lista com nove competências mais significativas que caracterizavam esses empreendedores. Com base nos estudos de McClelland, foi desenvolvido um modelo no qual classificaram dez competências empreendedoras, agrupadas em três conjuntos distintos: realização; planejamento; e poder (Lenzi, 2008; Zampier \& Takahashi, 2011).

Alguns autores teceram críticas aos estudos relativos a traços da personalidade empreendedora (Gartner, 1989), questionando as múltiplas definições de empreendedorismo e o uso de metodologias de pesquisa para distinguir uma personalidade sublime que se relacionasse com o desempenho (Kerr, Kerr \& $\mathrm{Xu}, 2018)$. Outros citaram a fraca relação entre características dos fundadores de negócio e o desempenho do empreendimento, desencadeado por resultados heterogêneos (Chandler \& Jansen, 1992; Herron \& Robson Jr., 1993; Masakure, Cranfield \& Henson, 2008). No entanto, para Fillion (1999), as discussões relativas a pequenas empresas estão intrinsicamente ligadas à figura do empreendedor.

Em alguns estudos relativos à análise do desempenho de novos empreendimentos, o empreendedor esteve ausente, como em Sandberg (1986), McDougall (1987) e McDougall, Robinson e Denisi (1992), sendo reconduzido por pesquisadores cujos resultados demonstraram o efeito das características do empreendedor nesse desempenho, em vez de somente elementos como estrutura e estratégia (Carland \& Carland, 1996).

Características empreendedoras como estabelecimento de metas, planejamento e monitoramento sistemático, independência e autoconfiança, compromentimento e exigência por qualidade e eficiência foram associadas a um maior desempenho organizazional (Fontenelle \& Hoeltgebaum, 2006). O desempenho foi também explicado por fatores do perfil empreendedor, constituído com base nas competências dispostas na literatura (Man, Lau \& Snape, 2008; Veit \& Gonçalves Filho, 2008; Lizote \& Verdinelli, 2014; Lizote \& Verdinelli, 2015; Eravia, Handayani \& Julina, 2015; Daciê, Espejo, Gimenez \& Camacho, 2017). 
Ainda que a presença de características empreendedoras não sejam garantia de sucesso em um negócio, certamente contribuem com o desempenho organizacional (Bomfim \& Torkomian, 2017). Outrossim, a ausência de características como liderança e a capacidade de assumir riscos podem representar barreiras para o desenvolvimento do empreendedorismo na agricultura familiar, na perspectiva Shumpteriana de inovação (Tomei \& Souza, 2014).

Diante desta heterogeneidade de resultados, surge o questionamento se de fato características empreendedoras são importantes para o desempenho organizacional e, com isso, provocar o despertamento para essa relação em ambientes poucos explorados como a produção rural. Embora haja falta de certa convergência na literura de empreendedorismo (Grégoire, Noel, Déry \& Béchard, 2006), a declaração da hipótese assumiu uma postura e um sinal, considerando a perspectiva que se espera advinda de um senso lógico, possivelmente aplicável (Gil, 2002). Conforme o exposto, estabeleceu-se a seguinte hipótese da pesquisa:

- Hipótese 1: As características do empreendedor influenciam positivamente o desempenho do empreendimento.

\subsection{Características do Empreendedor e as Proxies de Controle Gerencial}

À medida que o mundo se torna menos previsível, o controle torna-se mais complexo (Otley, 1994), de forma que o controle gerencial figura como suporte à gestão de mudanças, nesse ambiente dinâmico e imprevisível (Lima, Espejo, Pereira \& Frezatti, 2011). Embora autores como Johnson e Kaplan (1987) terem questionado a relevância do controle gerencial, outros indicaram a evolução de seus modelos (Lima et al., 2011), de forma que o sistema de controle gerencial, ao considerar também informações externas, amplia os subsídios para tomada de decisão (Mia, Chenhall, 1994; Chenhall, 2003). As informações gerenciais são tão importantes para as micros e pequenas empresas quanto são para as grandes (Santos, Dorow \& Beuren, 2016).

Considerando que o empreendedor é aquele que, além de estabelecer administra um negócio, tendo como objetivo principal lucro e crescimento (Carland, Hoy, Boulton \& Carland, 1984), a forma como toma decisões é o que o diferencia de gerentes. Essas decisões podem ser classificadas em críticas e não críticas, ou seja, decisões estratégicas e táticas (Hartman, 1954), uma vez que gerentes agem objetivamente enquanto que o empreendedor processa medidas mais subjetivas e fortemente ligadas a sua percepção (Fillion, 2000).

No entanto, no ambiente das MPEs, o empreendedor e o gestor frequentemente correspondem ao mesmo indivíduo, onde sua tomada de decisão é envolvida por elementos menos formais, evidenciando maior complexidade, mas também maior agilidade (Lobontiu \& Lobontiu, 2014). As características de ambos, portanto, não são exclusivas e ainda necessárias, ao grupo oposto (Fillion, 2000). Enfim, os empreendedores necessitam adotar práticas administrativas mais objetivas, voltadas à eficiência e à eficácia.

Por outro lado, a ausência de artefatos da contabilidade gerencial, que atuam tradicionalmente como precedentes dos discursos organizacionais, gera, nas organizações, a necessidade de proxies informacionais que possam substituir as informações gerenciais contábeis (Frezatti, Carter \& Barroso, 2014), denominadas proxies de controle gerencial. Neste sentido, depreende-se que a existência de ferramentas informais que auxiliam os processos de gestão (Daciê, 2016) coopera com a ideia de "Contabilidade sem Contabilidade", exposta por Frezatti, Carter e Barroso (2014).

Desse modo, a iniciativa de gerenciamento e controle é substancialmente determinada pelas características do empreendedor (Roper, 1998) e práticas de gestão estratégica condizem com o empreendedor (Carland et al., 1984). Advindo da revisão sistemática, Daciê et al. (2017) evidenciaram que o uso de proxies de controle gerencial é influenciado positivamente pelas características da orientação empreendedora. 
Há poucas pesquisas que abordem o uso de proxies de controle gerencial em MPEs, principalmente no agronegócio e conectadas a características empreendedoras, como é a proposta da presente investigação. Para isto, delineou-se a segunda hipótese da pesquisa:

- Hipótese 2: As características do empreendedor influenciam positivamente o uso de proxies de controle gerencial.

\subsection{Proxies de Controle Gerencial e o Desempenho}

A literatura clássica sobre controle gerencial buscou compreender a relação dos sistemas de controles gerenciais, maiormente, com a avaliação de desempenho dos subordinados. Exemplificando, Hopwood (1972) investigou o impacto do estilo de avaliação sobre o desempenho gerencial, enquanto que Otley (1978) mediu esse impacto não somente no desempenho gerencial, como também no desempenho organizacional. Govindarajan (1984), por sua vez, analisou a atuação da incerteza ambiental sobre o estilo de avaliação de desempenho.

Em uma outra dimensão de desempenho, Reid e Smith (2002) verificaram que a qualidade da informação gerada pela contabilidade gerencial em pequenas empresas tem relação direta com o desempenho delas. Kallunki, Laitinen e Silvola (2011) identificaram que os controles formais medeiam o efeito do sistema de planejamento de recursos empresarial e o desempenho não financeiro.

Contemporaneamente, as práticas de controle gerencial, associadas à estratégia de diferenciação, resultam em um desempenho superior (Junqueira, Dutra, Zanquetto Filho \& Gonzaga, 2016). Em concordância, Lima et al. (2011) manifestam que o alcance de um melhor desempenho está relacionado aos processos de gestão sistematizados, em que a maximização do retorno constitui um dos principais objetivos do negócio (Garg, Joubert \& Pellissier, 2004).

Como anunciado em Leite (2016), outros estudos abordaram a relação positiva do controle gerencial com o desempenho, como em Mizumoto et al. (2010) e Raifur (2013). A implementação de controles gerenciais demonstrou ser capaz de influenciar o desempenho, objetivo e subjetivo, em negócios familiares agrícolas de pequenos e médio porte, segundo Peake e Marshall (2017). Esse influxo também foi verificado por Maziriri e Mapuranga (2017), enquanto que Macinati e Anessi-Pessina (2014) verificaram uma fraca relação positiva entre a contabilidade gerencial e o desempenho financeiro.

Com base no exposto e considerando que a busca pela compreensão do desempenho organizacional, conectando a contabilidade gerencial a construtos de outras esferas do conhecimento, é uma conjuntura de desenvolvimento desse campo de estudos (Oyadomari, Frezatti, Mendonça Neto, Cardoso \& Bido, 2011), a terceira hipótese foi emergida:

- Hipótese 3: $\mathrm{O}$ uso de proxies de controle gerencial influencia positivamente o desempenho.

Destarte, as proxies de controle gerencial podem atuar como interlocutoras entre as características do empreendedor e o desempenho organizacional, tendo em vista o suporte oferecido para tomada de decisão (Oyadomari et al., 2011). Amparado nos estudos apresentados anteriormente (Rauch et al., 2009; Spillecke \& Bretell, 2013; Daciê, 2016; Leite, 2016) e subsidiando o objetivo geral da presente investigação, formulou-se a hipótese 4 :

- Hipótese 4: As proxies de controle gerencial atuam como mediadoras positivas na relação características do empreendedor e desempenho organizacional. 
Sobre as quatro hipóteses levantadas, pondera-se que, embora suas relações não sejam lógicas e simplistas, a proposta da investigação é justamente averiguá-las, mediante um modelo ainda não utilizado em pesquisas anteriores.

\subsection{Piscicultura}

A piscicultura corresponde a uma forma de exploração do agronegócio, fundamentando-se na criação de peixes e demais organismos aquáticos para comercialização e segundo o Ministério da Agricultura, Pecuária e Abastecimento do Brasil são atividades que pertencem a aquicultura, que é a criação de peixes em água doce (Eggers et al., 2016). Trata-se de uma atividade zootécnica que visa ao cultivo racional de peixes, exercendo particular controle sobre o crescimento, a reprodução e a alimentação destes animais (Galli \& Torloni, 1999).

Conforme Galli e Torloni (1999), a história da piscicultura no Brasil inicia com Rodolfo Von Ihering, em 1912, que acreditava que a potencialidade da criação de peixes seria comparável no futuro até mesmo com a produtividade da criação de galinhas. A piscicultura no Brasil pode ser desenvolvida predominantemente de duas maneiras: (1) em viveiros construídos para a criação de uma única espécie, geralmente utilizando alimentação artificial visando uma produção elevada, ou (2) em viveiros com várias espécies em conjunto e utilizando alimentação considerada não totalmente artificial, visando eficiência na combinação de diferentes espécies (Furtado, 1995; Eggers et al., 2016). Desta forma, no Brasil a piscicultura é uma atividade abrangente, encontradada tanto em micros e pequenos empreendimentos quanto na agricultura familiar ou em grandes produtores rurais.

\section{Procedimentos Metodológicos}

Epistemologicamente, a pesquisa fundamenta-se na perspectiva teórica positivista, de acordo com a categorização de Crotty (1998). O estudo foi desenvolvido mediante uma investigação empírica, caracterizado quanto ao objetivo como aplicado e descritivo (Cooper \& Schindler, 2016). A abordagem em relação ao problema contempla o uso do método cuja natureza dos dados é quantitativa.

A pesquisa foi realizada por meio de levantamento, também denominado survey (Martins \& Theóphilo, 2016), em uma dimensão do tempo cross sectional (Hair Jr. et al., 2009). As hipóteses levantadas no decorrer do referencial teórico objetivam testar a relação entre os construtos, atendendo, por fim, ao objetivo geral da pesquisa, conforme indicado no modelo conceitual (Figura 1).

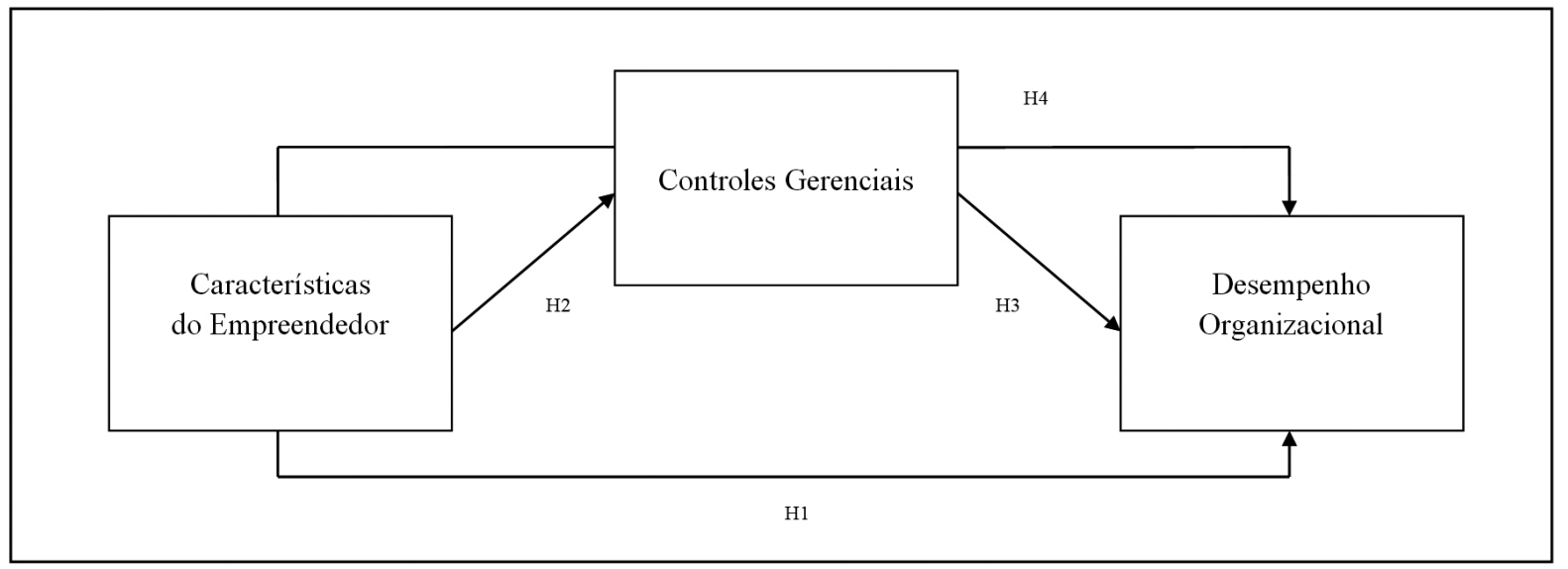

Figura 1. Desenho da pesquisa

Fonte: os autores (2019). 
Os construtos teóricos de segunda ordem utilizados foram: as características do empreendedor, proxies de controle gerencial e o desempenho organizacional financeiro e não financeiro. O construto "características do empreendedor" engloba dez variáveis explicativas, distribuídas em três construtos de primeira ordem (realização, planejamento e poder). Esse modelo é amplamente utilizado pelo Serviço Brasileiro de Apoio às Micro e Pequenas Empresas (Sebrae), para desenvolver empreendedores por meio do seu programa em parceria com a Conferência das Nações Unidas sobre Comércio e Desenvolvimento (Unctad) e com o Programa das Nações Unidas para o Desenvolvimento (PNUD), denominado Empretec, modelo esse advindo do estudo de McClelland (1987).

O construto controles gerenciais foi captado por meio de proxies informacionais, com base no estudo de Frezatti, Carter e Barroso (2014), mediante a ausência de sistemas mais robustos de controles gerenciais em micros e pequenas empresas. Para tanto, esse construto de segunda ordem formou-se a partir de quatro construtos de primeira ordem (plano de negócios; controles financeiros; fatores de marketing; e controle de pessoal) e 12 indicadores. O modelo foi adaptado com suporte em Leite (2016) e semelhantemente empregado por Daciê et al. (2017). Pontua-se que os quatro construtos de primeira ordem condizem com alguns controles anunciados nos modelos de Merchant \& Van Der Stede (2003) e Malmi \& Brown (2008).

O construto "desempenho" foi medido por autoavaliação e de forma subjetiva (Govindarajan, 1984), tendo em vista que micros e pequenas empresas possuem limitações quanto ao uso de medidas objetivas (Leite, 2016). Em relação aos tipos de desempenho, foram utilizados desempenho financeiro e não financeiro (Venkatraman \& Ramanujam, 1986; Brush \& Vanderwerf, 1992), por meio de quatro indicadores: crescimento das vendas; crescimento dos lucros; aumento do número de funcionários; e aumento na satisfação dos clientes.

Nos casos em que há limitação de fonte de dados sobre o desempenho da organização, em que a única possibilidade é o autorrelato do proprietário e/ou gerente, o crescimento e o volume dos negócios são as dimensões mais conhecidas por eles (Chandler \& Hanks, 1993). Sobre as medidas de crescimento, Wiklund (1999) considerou-as com maior adequabilidade para retratar o desempenho de pequenas empresas, sendo o crescimento das vendas a melhor medida de crescimento, e o crescimento do emprego uma medida importante, enquanto que o crescimento de investimento em ativo parece ser problemático.

Convém ponderar ainda que as variáveis explicativas correspondentes ao construto características do empreendedor foram captadas em relação as atitudes do produtor rural ao longo da vida e mediante outros negócios. Isso se deve ao entendimento de que, por se tratar de competências intrínsecas ao indivíduo, são independentes de ações pontuais que possa estar executando no momento. Já os construtos Proxies de Controle Gerencial e Desempenho são relativas a atividade de piscicultura, como indicado no início de cada seção do questionário.

A coleta dos dados ocorreu por meio de questionário, operacionalizada entre outubro e novembro de 2018. O instrumento (estruturação indicada na Figura 2) contém inicialmente 11 perguntas destinadas à caracterização dos piscicultores e respectivas pisciculturas. As perguntas correspondentes às variáveis explicativas totalizaram-se 26 , as quais utilizaram uma escala do tipo likert, com cinco pontos para as respostas. A fim de avaliar o questionário em relação ao cumprimento do seu objetivo, realizou-se um pré-teste com dois produtores rurais. 


\begin{tabular}{|c|c|c|c|c|c|c|}
\hline Parte & $\begin{array}{l}\text { Objetivos } \\
\text { Específicos }\end{array}$ & $\begin{array}{l}\text { Construtos } 2^{\circ} \\
\text { Ordem }\end{array}$ & $\begin{array}{l}\text { Construtos } \\
1^{\circ} \text { Ordem }\end{array}$ & Variáveis Explicativas & $\begin{array}{l}\text { Questões/ } \\
\text { Códigos }\end{array}$ & Referências \\
\hline 1 & - & - & - & - & 11 & - \\
\hline \multirow{10}{*}{2} & \multirow{10}{*}{$\begin{array}{l}\text { I) Identificar as } \\
\text { características } \\
\text { empreendedoras } \\
\text { predominantes } \\
\text { dos piscicultores }\end{array}$} & \multirow{10}{*}{$\begin{array}{l}\text { Características } \\
\text { do } \\
\text { Empreendedor }\end{array}$} & \multirow{5}{*}{ Realização } & $\begin{array}{l}\text { Busca de oportunidades } \\
\text { e iniciativa }\end{array}$ & \multirow{5}{*}{ CE1 a CE5 } & \multirow{10}{*}{$\begin{array}{l}\text { McClelland } \\
\text { (1987); Lenzi } \\
\text { (2008); } \\
\text { Schimidt e } \\
\text { Dreher (2008); } \\
\text { Schimidt e } \\
\text { Bohnenberger } \\
\text { (2009); Vilas } \\
\text { Boas (2015). }\end{array}$} \\
\hline & & & & Persistência & & \\
\hline & & & & Comprometimento & & \\
\hline & & & & $\begin{array}{l}\text { Exigência de qualidade e } \\
\text { eficiência }\end{array}$ & & \\
\hline & & & & Correr riscos calculados & & \\
\hline & & & \multirow{3}{*}{ Planejamento } & Busca de informações & \multirow{3}{*}{ CE6 a CE8 } & \\
\hline & & & & $\begin{array}{l}\text { Estabelecimento de } \\
\text { metas }\end{array}$ & & \\
\hline & & & & $\begin{array}{l}\text { Planejamento e } \\
\text { monitoramento } \\
\text { sistemático }\end{array}$ & & \\
\hline & & & \multirow{2}{*}{ Poder } & $\begin{array}{l}\text { Independência e } \\
\text { autoconfiança }\end{array}$ & \multirow{2}{*}{ CE9 a CE10 } & \\
\hline & & & & $\begin{array}{l}\text { Persuasão e rede de } \\
\text { contatos }\end{array}$ & & \\
\hline \multirow{12}{*}{3} & \multirow{12}{*}{$\begin{array}{l}\text { II) Caracterizar a } \\
\text { proxies de controle } \\
\text { gerencial utilizadas } \\
\text { como ferramentas } \\
\text { de controle } \\
\text { gerencial pelos } \\
\text { piscicultores; }\end{array}$} & \multirow{12}{*}{$\begin{array}{l}\text { Proxies de } \\
\text { Controle } \\
\text { Gerencial }\end{array}$} & \multirow{3}{*}{$\begin{array}{l}\text { Planejamento } \\
\text { (plano de } \\
\text { negócios) }\end{array}$} & $\begin{array}{l}\text { Realização de plano de } \\
\text { negócios }\end{array}$ & \multirow{3}{*}{$\begin{array}{l}\text { PCG1 a } \\
\text { PCG3 }\end{array}$} & \multirow{12}{*}{$\begin{array}{l}\text { Mehralizadeh } \\
\text { Sajady (2006); } \\
\text { Sebrae (2008); } \\
\text { Mizumoto } \\
\text { et al. (2010); } \\
\text { Schaefer } \\
\text { (2012); Raifur } \\
\text { (2013); Leite } \\
\text { (2016); Daciê et } \\
\text { al. (2017). }\end{array}$} \\
\hline & & & & $\begin{array}{l}\text { Realização de plano de } \\
\text { ação }\end{array}$ & & \\
\hline & & & & Uso do plano de negócios & & \\
\hline & & & \multirow{3}{*}{$\begin{array}{l}\text { Controles } \\
\text { financeiros }\end{array}$} & $\begin{array}{l}\text { Conhecimento de fluxo } \\
\text { de caixa }\end{array}$ & \multirow{3}{*}{$\begin{array}{l}\text { PCG4 a } \\
\text { PCG6 }\end{array}$} & \\
\hline & & & & $\begin{array}{l}\text { Utilização de fluxo de } \\
\text { caixa }\end{array}$ & & \\
\hline & & & & $\begin{array}{l}\text { Registro dos gastos da } \\
\text { produção }\end{array}$ & & \\
\hline & & & \multirow{3}{*}{$\begin{array}{l}\text { Fatores de } \\
\text { marketing }\end{array}$} & Pesquisa de mercado & \multirow{3}{*}{$\begin{array}{l}\text { PCG7 a } \\
\text { PCG9 }\end{array}$} & \\
\hline & & & & $\begin{array}{l}\text { Contato com } \\
\text { fornecedores }\end{array}$ & & \\
\hline & & & & Análise do ambiente & & \\
\hline & & & \multirow{3}{*}{$\begin{array}{l}\text { Controle de } \\
\text { pessoal }\end{array}$} & Controle de ações & \multirow{3}{*}{$\begin{array}{l}\text { PCG10 a } \\
\text { PCG12 }\end{array}$} & \\
\hline & & & & Recrutamento e seleção & & \\
\hline & & & & Treinamento & & \\
\hline \multirow[b]{4}{*}{4} & \multirow{4}{*}{$\begin{array}{l}\text { III) Identificar o } \\
\text { desempenho } \\
\text { das pisciculturas } \\
\text { no decorrer das } \\
\text { atividades }\end{array}$} & \multirow[b]{4}{*}{-} & \multirow[b]{4}{*}{ Desempenho } & Crescimento das vendas & ID1 & \multirow{4}{*}{$\begin{array}{l}\text { Chandler e } \\
\text { Hanks (1993); } \\
\text { Wiklund } \\
\text { (1999); Haber e } \\
\text { Reichel (2005); } \\
\text { Brackburn e } \\
\text { Hart (2013); } \\
\text { Vilas Boas } \\
\text { (2015) Leite } \\
\text { (2016); Daciê et } \\
\text { al. (2017). }\end{array}$} \\
\hline & & & & Crescimento dos lucros & ID2 & \\
\hline & & & & $\begin{array}{l}\text { Aumento do número de } \\
\text { funcionários }\end{array}$ & ID3 & \\
\hline & & & & $\begin{array}{l}\text { Aumento da satisfação } \\
\text { dos clientes }\end{array}$ & ID4 & \\
\hline
\end{tabular}

Figura 2. Estruturação do instrumento de coleta de dados

Fonte: os autores (2019). 
Determinou-se a população de maneira não probabilística e por conveniência (Cooper \& Schindler, 2016), correspondente a 98 piscicultores, atendidos por um programa de assistência técnica, no Estado de Mato Grosso do Sul. Esse programa oferece suporte a produtores rurais de diversas cadeias produtivas do agro, cuja metodologia contempla a assistência técnica relativa a atividade e a assistência gerencial aos negócios rurais.

A parceria firmada entre os pesquisadores e a instituição propiciou a aplicação do questionário e o alcance da taxa de resposta em 70,4\%. A amostra final resultou em 69 pisciculturas, compreendidas por pequenos produtores e produtores de piscicultura familiar, distribuídos em doze municípios do referido estado. Os questionários foram aplicados fisicamente.

Quanto à representatividade amostral, foi adotada a análise do poder estatístico, indicado por Cohen (1988) como "a probabilidade de produzir resultados estatisticamente significativos". Para o cálculo, utilizou-se o software $\mathrm{G}^{\star}$ Power 3.1.9, empregando os seguintes parâmetros: tamanho do efeito $=0,15$; erro do tipo $\mathrm{I}=0,05$; poder do teste $=0,80$ e maior $n .^{\circ}$ de preditores $=2$ (variável latente Desempenho recebe duas setas no modelo de caminhos), resultando na necessidade de 68 amostras.

Segundo Ringle, Silva e Bido (2014), é o número de preditores que define a amostra mínima necessária em Structural Equation Modeling (SEM) (modelagem de equações estruturais), com ajustes por partial least square (PLS) (mínimos quadrados parciais), utilizada nesse estudo.

Além do amparo na análise do poder estatístico, Hair Jr. et al. (2009) apontam que o menor tamanho de uma amostra para análise fatorial, técnica que na categoria confirmatória é o primeiro passo da SEM, deve ser de 50 observações. Hair Jr. et al. (2016) reportam que o tamanho da amostra pode ser igual ou superior a dez vezes o maior número de preditores de uma variável latente do modelo, porém recomendam que sejam considerados ainda o modelo e as características do dados.

Os dados foram analisados por meio de análise multivariada, com a técnica de modelagem de equações estruturais (SEM), indicado para verificar a consistência dos dados a priori com os construtos estabelecidos (Mingoti, 2005), e quando se pretende verificar simultâneas relações entre diferentes construtos (Hair Jr. et al. , 2016). Utilizou-se, para isso, o software SmartPLS (versão 3.2.8). O uso de SEM, com ajustes por partial least square, é menos sensível a considerações sobre tamanho amostral e alivia a necessidade de normalidade de dados, sendo mais adequada para amostras pequenas na análise de SEM (Hair Jr. et al., 2009; Kallunli, Laitinen \& Silvola, 2011).

Além disso, a mediação de construtos foi objeto dessa pesquisa. Conforme Hair Jr. et al. (2016), o uso de SEM permite a investigação de mediação e moderação, onde a moderação é indicada para casos em que a relação entre a variável exógena e endógena do modelo é inconstante e depende de uma terceira variável. A mediação é a análise que verifica a influência de uma terceira variável na relação linear entre dois construtos. Esse trabalho verifica a influência da variável "próxies de controle gerencial" na relação linear entre "características do empreendedor" e "desempenho", sendo assim, a mediação foi averiguada. Seguem a análise e a discussão dos resultados.

\section{Análise e Discussão dos Resultados}

Os dados levantados na primeira parte do questionário, com a finalidade de caracterizar as pisciculturas e os piscicultores, mostram que há uma predominância de produtores com gênero masculino, $56,5 \%$ tem mais de 45 anos e a formação escolar de maior ocorrência é o ensino médio. Do total da amostra, 26,1\% alegaram já ter sido responsáveis pela abertura de outros 2 negócios e $26,1 \%$ de 4 ou mais, o que sugere certa persistência dos produtores em empreender e diversificar suas atividades. 
Quanto à atividade de piscicultura, 94,2\% possuem unidade produtiva de pequeno porte (de 1 ha a 3 ha de lâmina d'água) e 5,8\% de médio porte (de 3,1 ha a 20 ha de lâmina d'água), não havendo nenhuma de grande porte. Essa categorização segue conforme a LEI n. ${ }^{\circ} 1.653$, de 10 de janeiro de 1996, que define e disciplina a piscicultura no Estado de Mato Grosso do Sul. Em relação ao sistema de produção, $81,2 \%$ utilizam o sistema semi-intesivo, sinalizando uma produção comercial com a busca por maior produtividade.

Diferentemente, a proxies de controle gerencial tiveram suas medidas de moda e mediana, maiormente entre 1 e 3, e média acima de 3 apenas em duas variáveis (do total de 12), indicando baixa presença na amostra. No construto "desempenho" (com 4 variáveis), uma variável gerou valor médio acima de 3, e o valor de moda e mediana frequente foi um, indicando que o desempenho desses empreendimentos tem se mostrado baixo. Seguir-se-á, dessa forma, com as análises da estatística multivariada.

Antes de iniciar o processo SEM, foram feitas as verificações necessárias relativas aos dados como a constatação da inexitência de missings e o teste de Normalidade dos Dados, utilizando o software Minitab", atestando a não normalidade dos dados. Salienta-se que não foram analisados graus de liberdade por não serem significativos em PLS (SEM, por mínimos quadrados parciais) como são em SEM por máxima verossimilhança (Hair Jr. et al., 2009).

Posteriormente à estimação do modelo, cuja configuração de análise é padrão no SmartPLS ${ }^{\circledast}$, as análises são dispostas em duas fases: primeiro, examinou-se o modelo de mensuração, no qual é avaliada a confiabilidade, a validade convergente (variance extracted) e a validade discriminante (discriminant validity). A segunda fase consistiu-se na análise do modelo estrutural, com a verificação do coeficiente de determinação (R2), a relevância preditiva (Q2), o tamanho dos efeitos (f2) e o tamanho e a significância dos coeficientes de caminhos (path coefficients), como disposto por Nascimento e Macedo (2016).

$\mathrm{Na}$ análise do modelo de mensuração (modelo 1), o alpha de cronbach do construto realização ficou abaixo do limite recomendado $(<0.7)$, entretanto entre os limeites aceitáveis para pesquisa exploratória (entre 0.6 e 0.7). Hair Jr. et al. (2016) mencionam que PLS-SEM caracteriza-se como pesquisa exploratória, utilizado, principalmente, para desenvolver teorias.

Uma vez que o alpha de cronbach e a confiabilidade composta objetivam verificar se a amostra é livre de vieses e se as respostas conjuntamente são confiáveis, os valores apresentados pelo modelo mostram essa confiança. Quanto à validade convergente, os valores da variância média extraída (AVE) do construto realização (0.435) e desempenho (0.483) estiveram abaixo do recomendável (0.5), valores estes apresentados na Tabela 1, a seguir.

Tabela 1

Indicadores de confiabilidade e AVE

\begin{tabular}{lccc}
\hline \multicolumn{1}{c}{ Variáveis Latentes } & $\begin{array}{c}\text { Alfa de } \\
\text { Cronbach }\end{array}$ & $\begin{array}{c}\text { Confiabilidade } \\
\text { composta }\end{array}$ & $\begin{array}{c}\text { Variância Média } \\
\text { Extraída (AVE) }\end{array}$ \\
\hline Realização & $\mathbf{0 . 6 6 1}$ & 0.786 & $\mathbf{0 . 4 3 5}$ \\
\hline Planejamento & 0.743 & 0.855 & 0.664 \\
\hline Poder & 0.716 & 0.876 & 0.779 \\
\hline Planejamento (Plano de Negócios) & 0.912 & 0.945 & 0.851 \\
\hline Controles Financeiros & 0.864 & 0.917 & 0.786 \\
\hline Fatores de Marketing & 0.872 & 0.922 & 0.798 \\
\hline Controle de Pessoal & 0.974 & 0.983 & 0.950 \\
\hline Desempenho & 0.762 & 0.783 & $\mathbf{0 . 4 8 3}$ \\
\hline
\end{tabular}

Fonte: dados da pesquisa (2019). 
Ainda sobre a validade convergente, a carga fatorial da variável CE2 (0.390) não atendeu ao limite mínimo (> 0.5) para que seja considerada significativa (Ringle, Silva \& Bido, 2014). Mediante esses fatores, associados ainda ao valor de AVE do construto realização, decidiu-se pela exclusão dessa variável, como sugerido por Ringle, Silva e Bido (2014). Estimou-se novamente o modelo (modelo 2) e, com a exclusão de CE2, o valor AVE do construto realização gerado foi de 0.520; o alfa de cronbach do construto foi de 0.683; e o valor AVE do construto desempenho também foi elevado (0.491).

No modelo 2, a validade discriminante por Fornell Larcker (1981) foi demonstrada no modelo horizontal. Pelo critério de cargas cruzadas, a variável CE5 apresentou carga fatorial maior em outro construto (planejamento) que no construto a que ela corresponde (realização). Todas as outras variáveis apresentam maiores cargas em seus respectivos construtos (análise horizontal), em conformidade com Chin (1998, apud Hair Jr. et al., 2009) e Ringle, Silva e Bido (2014). Segue, na Tabela 2, a validade discriminante por cargas cruzadas.

Tabela 2

Validade discriminante por cargas cruzadas - Chin (1998)

\begin{tabular}{|c|c|c|c|c|c|c|c|c|}
\hline $\begin{array}{c}\text { Variáveis } \\
\text { Explicativas }\end{array}$ & Realização & Planejamento & Poder & $\begin{array}{c}\text { Planejamento } \\
\text { (Plano de } \\
\text { Negócios) }\end{array}$ & $\begin{array}{c}\text { Controles } \\
\text { Financeiros }\end{array}$ & $\begin{array}{c}\text { Fatores } \\
\text { de } \\
\text { Marketing }\end{array}$ & $\begin{array}{c}\text { Controle } \\
\text { de } \\
\text { Pessoal }\end{array}$ & Desempenho \\
\hline CE1 & 0.733 & 0.475 & 0.483 & 0.441 & 0.345 & 0.267 & 0.265 & 0.262 \\
\hline CE3 & 0.806 & 0.432 & 0.459 & 0.268 & 0.313 & 0.246 & 0.033 & 0.036 \\
\hline CE4 & 0.750 & 0.263 & 0.460 & 0.281 & 0.397 & 0.205 & 0.055 & -0.022 \\
\hline CE5 & 0.573 & 0.663 & 0.477 & 0.344 & 0.389 & 0.376 & 0.059 & -0.068 \\
\hline CE6 & 0.624 & 0.832 & 0.540 & 0.463 & 0.430 & 0.522 & 0.111 & -0.109 \\
\hline CE7 & 0.566 & 0.887 & 0.509 & 0.510 & 0.499 & 0.564 & 0.233 & 0.016 \\
\hline CE8 & 0.384 & 0.716 & 0.527 & 0.522 & 0.396 & 0.261 & 0.229 & 0.067 \\
\hline CE9 & 0.601 & 0.529 & 0.880 & 0.419 & 0.467 & 0.190 & 0.092 & 0.109 \\
\hline CE10 & 0.562 & 0.604 & 0.885 & 0.458 & 0.482 & 0.383 & 0.140 & -0.032 \\
\hline PCG1 & 0.383 & 0.520 & 0.437 & 0.933 & 0.468 & 0.184 & 0.204 & -0.066 \\
\hline PCG2 & 0.504 & 0.553 & 0.491 & 0.884 & 0.563 & 0.261 & 0.356 & 0.128 \\
\hline PCG3 & 0.404 & 0.602 & 0.443 & 0.950 & 0.502 & 0.241 & 0.260 & -0.017 \\
\hline PCG4 & 0.548 & 0.574 & 0.587 & 0.572 & 0.914 & 0.259 & 0.373 & 0.376 \\
\hline PCG5 & 0.367 & 0.462 & 0.478 & 0.536 & 0.890 & -0.040 & 0.266 & 0.212 \\
\hline PCG6 & 0.404 & 0.389 & 0.339 & 0.353 & 0.855 & 0.138 & 0.305 & 0.263 \\
\hline PCG7 & 0.421 & 0.553 & 0.363 & 0.226 & 0.122 & 0.836 & 0.193 & -0.011 \\
\hline PCG8 & 0.297 & 0.485 & 0.279 & 0.200 & 0.156 & 0.908 & 0.320 & 0.048 \\
\hline PCG9 & 0.330 & 0.480 & 0.239 & 0.246 & 0.109 & 0.933 & 0.229 & 0.001 \\
\hline PCG10 & 0.154 & 0.243 & 0.142 & 0.268 & 0.360 & 0.282 & 0.991 & 0.560 \\
\hline PCG11 & 0.126 & 0.205 & 0.104 & 0.281 & 0.289 & 0.253 & 0.964 & 0.582 \\
\hline PCG12 & 0.146 & 0.225 & 0.137 & 0.327 & 0.395 & 0.283 & 0.969 & 0.555 \\
\hline ID1 & -0.011 & -0.138 & 0.028 & -0.060 & 0.261 & -0.250 & 0.026 & 0.578 \\
\hline ID2 & 0.069 & 0.026 & 0.112 & 0.091 & 0.350 & -0.116 & 0.188 & 0.710 \\
\hline ID3 & 0.077 & -0.002 & 0.023 & 0.029 & 0.249 & 0.090 & 0.696 & 0.873 \\
\hline ID4 & 0.011 & -0.050 & -0.061 & -0.113 & 0.102 & 0.070 & 0.172 & 0.603 \\
\hline
\end{tabular}

Fonte: dados da pesquisa (2019). 
$\mathrm{Na}$ análise do modelo estrutural, os valores de $\mathrm{Q}^{2}$ e $\mathrm{f}^{2}$ foram obtidos no módulo Blindfolding no SmartPLS ${ }^{\circledast}$ (Ringle, Silva \& Bido, 2014), utilizando-se a distância de omissão de 7 pontos. Os resultados apontaram $\mathrm{Q}^{2}$ de todos os construtos > 0 (Hair Jr. et al., 2016), com efeito $\left(\mathrm{f}^{2}\right)$ médio alto dos construtos no modelo (Ringle, Silva \& Bido, 2014).

Os valores de $\mathrm{R}^{2}$ apontam efeitos grandes do modelo estrutural em todos os construtos, exceto no construto "desempenho" para o qual o efeito é médio, ou seja, $20 \%$ da variação de desempenho são desencadeadas por características do empreendedor e pelas proxies de controle gerencial. As características do empreendedor não preveem poder explicativo $\left(\mathrm{R}^{2}\right)$, pois é o construto exógeno e antecede às outras VLs no modelo estrutural.

Para a análise do tamanho e significância dos coeficientes de caminhos entre os construtos, segue o modelo completo (Figura 3), com as cargas fatoriais do modelo de mensuração e com os coeficientes de caminho do modelo estrutural. Por meio da técnica de bootstrapping, verificou-se que todas as relações entre variáveis latentes foram significativas, com valores de $\mathrm{p}<0,05$, ou seja, os construtos utilizados no modelo afetam uns aos outros, conforme previamente esperado e estabelecido pelas hipóteses, independente do sinal desse efeito.

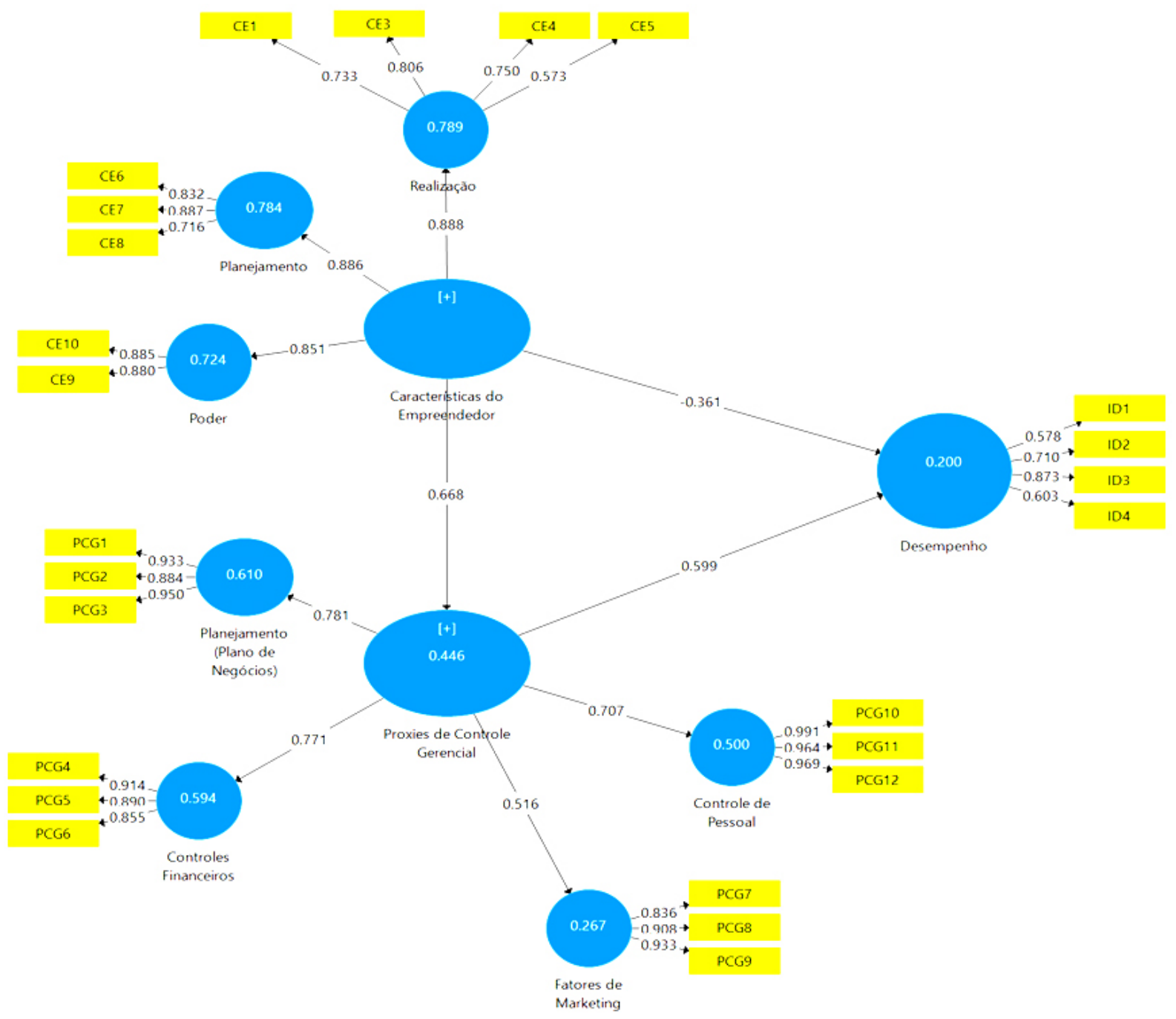

Figura 3. Modelo com coeficientes de caminho (path coeficiente)

Fonte: dados da pesquisa (2019). 
Em decorrência de o indicador AVE do construto desempenho ter ficado abaixo do limite mínimo de 0.5; a variável CE5, na validade discriminante, apresentar maior relação com o construto planejamento; e o indicador ID1 não ser significativo a 0.05 , optou-se pela modificação do modelo, mesmo considerando que o escopo do estudo seja verificar o efeito mediador das proxies de controle gerencial. Essa ação é apoiado pela estratégia de desenvolvimento de modelos, o qual além de ser aplicado para testar um modelo empiricamente, SEM também oferece ideias sobre sua reespecificação (Hair Jr. et al., 2009).

Teoricamente, compreende-se que essa reespecificação é amparada pela heterogeneidade nos resultados apresentados na literatura, concernentes a características do empreendedor e desempenho (Chandler \& Jansen, 1992; Herron \& Robson Jr., 1993; Carland \& Carland, 1996; Lizote \& Verdinelli, 2014), e pela discussão em torno das medidas de desempenho objetivas versus subjetivas, financeiras versus não financeiras (Venkatraman \& Ramanujam, 1986; Murphy, Trailer \& Hill, 1996; Richard et al., 2009; Brito \& Brito, 2012).

O modelo alternativo (modelo 3), além de excluir a variável ID1, alocou a variável CE5 do construto realização para o construto planejamento (indicado no critério cargas cruzadas), a fim de verificar se essa mudança produziria um melhor ajuste. Manteve-se ainda a exclusão de CE2, já realizada na análise do modelo de mensuração 1 . Os resultados da confiabilidade e da validade convergente são apresentados na Tabela 3.

Tabela 3

Indicadores de confiabilidade e AVE pós reespecificação do modelo

\begin{tabular}{lccc}
\hline \multicolumn{1}{c}{ Variáveis Latentes } & Alfa de Cronbach & $\begin{array}{c}\text { Confiabilidade } \\
\text { Composta }\end{array}$ & $\begin{array}{c}\text { Variância Média } \\
\text { Extraída (AVE) }\end{array}$ \\
\hline Realização & 0.752 & 0.858 & 0.669 \\
\hline Planejamento & 0.807 & 0.875 & 0.639 \\
\hline Poder & 0.716 & 0.876 & 0.779 \\
\hline Planejamento (Plano de Negócios) & 0.912 & 0.945 & 0.851 \\
\hline Controles Financeiros & 0.864 & 0.917 & 0.786 \\
\hline Fatores de Marketing & 0.872 & 0.922 & 0.798 \\
\hline Controle de Pessoal & 0.974 & 0.983 & 0.950 \\
\hline Desempenho & $\mathbf{0 . 6 4 0}$ & 0.766 & 0.531 \\
\hline
\end{tabular}

Fonte: Dados da pesquisa (2019).

Com a exclusão da variável ID1, o construto desempenho gerou uma redução de 0.762 para 0.640 no valor do alfa de cronbach, ainda aceitável para pesquisas exploratórias. O valor de 0.766 para a confiabilidade composta do construto "desempenho" reforça a presença da confiabilidade desses indicadores. Com todos os valores AVE e cargas fatoriais $>0.5$, a validade convergente foi atestada. A validade discriminante do modelo reespecificado foi expressa pelos dois critérios. Certificou-se ainda a validade discriminante pelo critério HTMT, proposto por Henseler et al. (2015 apud Hair Jr. et al., 2016), para o qual o intervalo de confiança não deve incluir o valor 1 na combinação dos construtos, fato este evidenciado por meio do bootstrapping que segue apresentado na Tabela 4. 
Tabela 4

Relações entre construtos (bootstrapping) pós reespecificação do modelo

\begin{tabular}{|c|c|c|c|c|c|}
\hline Relações entre Variáveis Latentes & $\begin{array}{l}\text { Amostra } \\
\text { Original }\end{array}$ & $\begin{array}{l}\text { Média da } \\
\text { Amostra }\end{array}$ & $\begin{array}{l}\text { Desvio } \\
\text { Padrão }\end{array}$ & $\begin{array}{l}\text { Estatística } \\
\qquad \mathrm{T}\end{array}$ & $\begin{array}{l}\text { Valores } \\
\text { de P }\end{array}$ \\
\hline Características do Empreendedor $\rightarrow$ Realização & 0.772 & 0.768 & 0.074 & 10.381 & 0.000 \\
\hline Características do Empreendedor $\rightarrow$ Planejamento & 0.879 & 0.884 & 0.028 & 31.012 & 0.000 \\
\hline Características do Empreendedor $\rightarrow$ Poder & 0.853 & 0.853 & 0.033 & 25.890 & 0.000 \\
\hline $\begin{array}{l}\text { Características do Empreendedor } \rightarrow \text { Proxies de } \\
\text { Controle Gerencial }\end{array}$ & 0.665 & 0.668 & 0.057 & 11.627 & 0.000 \\
\hline Características do Empreendedor $\rightarrow$ Desempenho & -0.364 & -0.390 & 0.130 & 2.797 & 0.005 \\
\hline $\begin{array}{l}\text { Proxies de Controle Gerencial } \rightarrow \text { Planejamento (Plano } \\
\text { de Negócios) }\end{array}$ & 0.779 & 0.778 & 0.063 & 12.447 & 0.000 \\
\hline Proxies de Controle Gerencial $\rightarrow$ Controles Financeiros & 0.769 & 0.775 & 0.055 & 14.003 & 0.000 \\
\hline Proxies de Controle Gerencial $\rightarrow$ Fatores de Marketing & 0.517 & 0.511 & 0.147 & 3.512 & 0.000 \\
\hline Proxies de Controle Gerencial $\rightarrow$ Controle de Pessoal & 0.710 & 0.699 & 0.103 & 6.890 & 0.000 \\
\hline Proxies de Controle Gerencial $\rightarrow$ Desempenho & 0.621 & 0.669 & 0.136 & 4.571 & 0.000 \\
\hline
\end{tabular}

Fonte: dados da Pesquisa (2019).

A significância das relações com a análise do teste $t$ no modelo de Estrutural e de Mensuração foram significativas a $5 \%$ e $p$-value $<0,05$. Ainda comparando os modelos 2 e 3 , na análise do modelo estrutural, os resultados (Tabela 5) apontam uma redução em relação ao modelo 2, no $\mathrm{R}^{2}$ nos construtos "realização", "planejamento" "proxies de controle gerencial", planejamento" (plano de negócios) e "controles financeiros". Com exceção de realização, as alterações, nos demais, foram muito pequenas. Já, os construtos "poder", "fatores de marketing", "controle de pessoal" e "desempenho" tiveram aumento nos seus respectivos $\mathrm{R}^{2}$, ou seja, o modelo Estrutural agora representa $21,7 \%$ da variação de desempenho.

Tabela 5

Coeficientes de determinação, relevância preditiva e tamanho do efeito pós reespecificação

\begin{tabular}{lccc}
\hline \multicolumn{1}{c}{ Variáveis Latentes } & $\mathbf{R}^{\mathbf{2}}$ & $\mathbf{Q}^{\mathbf{2}}$ & $\mathbf{f}^{\mathbf{2}}$ \\
\hline Características do Empreendedor & - & - & 0.329 \\
\hline Realização & 0.596 & 0.368 & 0.332 \\
\hline Planejamento & 0.773 & 0.454 & 0.394 \\
\hline Poder & 0.727 & 0.540 & 0.308 \\
\hline Proxies de Controle Gerencial & 0.443 & 0.160 & 0.294 \\
\hline Planejamento (Plano de Negócios) & 0.607 & 0.479 & 0.610 \\
\hline Controles Financeiros & 0.592 & 0.432 & 0.512 \\
\hline Fatores de Marketing & 0.268 & 0.187 & 0.531 \\
\hline Controle de Pessoal & 0.504 & 0.446 & 0.760 \\
\hline Desempenho & 0.217 & 0.079 & 0.159 \\
\hline
\end{tabular}

Fonte: dados da Pesquisa (2019).

A Tabela 6 mostra os efeitos diretos, indiretos e totais do modelo reespecificado. Para as relações diretas e indiretas, a variação foi inexpressiva, de forma que o efeito total de características do empreendedor no desempenho é de $4,9 \%$ (direto - $36,4 \%$ e indireto $41,3 \%$ ), uma variação de $1 \%$ em relação ao modelo 2. O efeito direto de características do empreendor no uso de proxies de controle gerencial ficou em $66,5 \%$. Já, o efeito de proxies de Controle Gerencial no desempenho foi de $62,1 \%$. 
Tabela 6

Valores dos efeitos diretos, indiretos e totais do modelo reespecificado

\begin{tabular}{lccc}
\hline \multicolumn{1}{c}{ Relações entre Variáveis Latentes } & $\begin{array}{c}\text { Efeitos } \\
\text { Diretos }\end{array}$ & $\begin{array}{c}\text { Efeitos } \\
\text { Indiretos }\end{array}$ & $\begin{array}{c}\text { Efeitos } \\
\text { Totais }\end{array}$ \\
\hline Características do Empreendedor $\rightarrow$ Realização & 0.772 & 0.000 & 0.772 \\
\hline Características do Empreendedor $\rightarrow$ Planejamento & 0.879 & 0.000 & 0.879 \\
\hline Características do Empreendedor $\rightarrow$ Poder & 0.853 & 0.000 & 0.853 \\
\hline Características do Empreendedor $\rightarrow$ Proxies de Controle Gerencial & 0.665 & 0.000 & 0.665 \\
\hline Características do Empreendedor $\rightarrow$ Planejamento (Plano de Negócios) & 0.000 & 0.519 & 0.519 \\
\hline Características do Empreendedor $\rightarrow$ Controles Financeiros & 0.000 & 0.512 & 0.512 \\
\hline Características do Empreendedor $\rightarrow$ Fatores de Marketing & 0.000 & 0.344 & 0.344 \\
\hline Características do Empreendedor $\rightarrow$ Controle de Pessoal & 0.000 & 0.472 & 0.472 \\
\hline Características do Empreendedor $\rightarrow$ Desempenho & -0.364 & 0.413 & 0.049 \\
\hline Proxies de Controle Gerencial $\rightarrow$ Planejamento (plano de negócios) & 0.779 & 0.000 & 0.779 \\
\hline Proxies de Controle Gerencial $\rightarrow$ Controles Financeiros & 0.769 & 0.000 & 0.769 \\
\hline Proxies de Controle Gerencial $\rightarrow$ Fatores de Marketing & 0.517 & 0.000 & 0.517 \\
\hline Proxies de Controle Gerencial $\rightarrow$ Controle de Pessoal & 0.710 & 0.000 & 0.710 \\
\hline Proxies de Controle Gerencial $\rightarrow$ Desempenho & 0.621 & 0.000 & 0.621 \\
\hline
\end{tabular}

Fonte: dados da pesquisa (2019).

Algumas considerações decorrentes desses efeitos serão retomadas posteriormente. Considerando que o modelo reespecificado atendeu aos problemas de ajustes indicados anteriormente, ele foi empregado na análise subsequente, a fim de cumprir o objetivo geral da pesquisa.

\subsection{Análise de Mediação das Proxies de Controle Gerencial}

Para verificar a mediação, Hair Jr. et al. (2016) apontam que é necessário uma série de análises. O primeiro passo consiste em verificar se há significância do efeito indireto entre variável independente $(V I)$ e dependente $(V D)$ por meio de outro construto (variável mediadora - VM). Outro passo é avaliar o efeito direto: se ele não for significativo mediante um efeito indireto significativo, indica que a mediação é indireta. Se o efeito direto for significativo assim como o indireto, pode se distinguir entre mediação complementar (efeito direto e indireto significativos com a mesma direção) ou competitiva (efeito direto e indireto significativos com direções opostas).

Dessa forma, os autores expõem, com base em Zhao, Lynch e Chen (2010), que uma não mediação é postulada quando, no modelo em que estão presentes todos os construtos, o efeito direto entre a variável latente exógena e endógena é significativo, mas o efeito indireto não é, ou quando nem o efeito direto, nem o indireto são significativos. No modelo dessa pesquisa, tanto o efeito direto $(t=2.797)$, quanto $o$ indireto $(\mathrm{t}=4.288)$ são significativos.

Seguindo as análises, Hair Jr. et al. (2009) descrevem um série de 4 passos com vistas a realizar uma análise de mediação. Os passos serão descritos, utilizando-se os construtos dessa pesquisa (Figura 4) e, em seguida, discorre-se sobre as análises. 


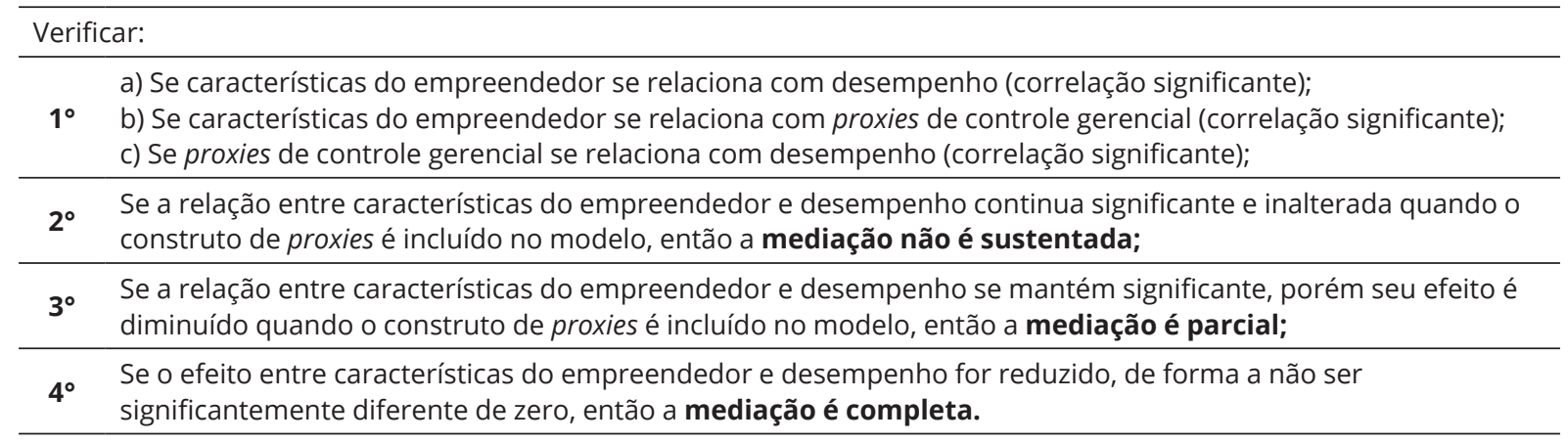

Figura 4. Fases para análise de mediação

Fonte: os autores (2019).

A fim de cumprir a análise de mediação, como disposto na Figura 4, realizaram-se os testes de Verificação. Para realizar o teste proposto, é necessário rodar os dados de dois em dois construtos, uma vez que a $2^{\mathrm{a}}$ etapa da análise sugere observar a significância da relação entre os dois construtos quando o suposto construto "mediador" é iserido no modelo. Na Figura 5, são apresentados os resultados dessa rodagem por meio da técnica bootstrapping, que efetuou 1000 reamostragens da amostra inicial. Os coeficientes das figuras do teste são os resultados do teste- $t$, a fim de verificar a significância das relações (utilizando o valor de referência de $t=2.000$, de 60 a 120 graus de liberdade, conforme tabela de distribuição $t$ ).

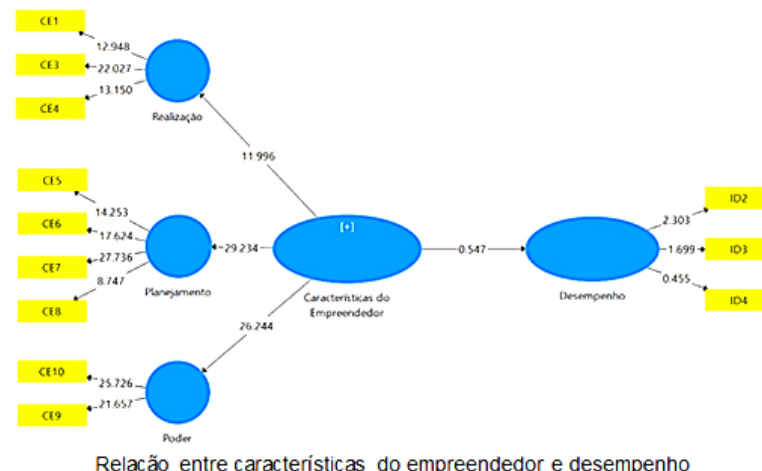

Relação entre caracteristicas do empreendedor e desempenho

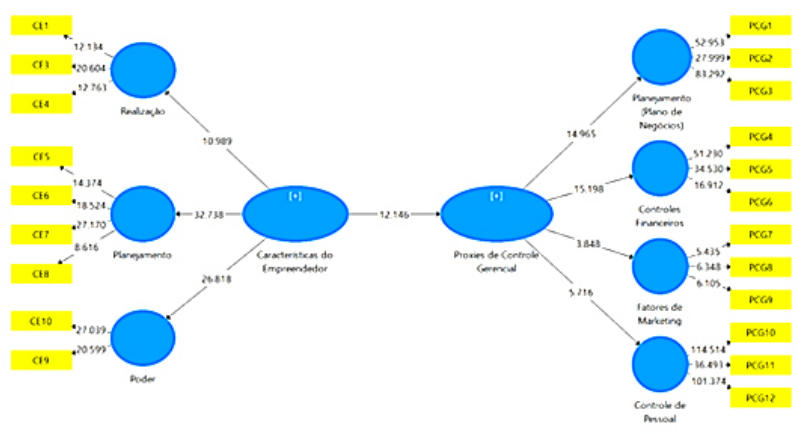

Relação entre caracteristicas do empreendedor e proxies de controle gerencial

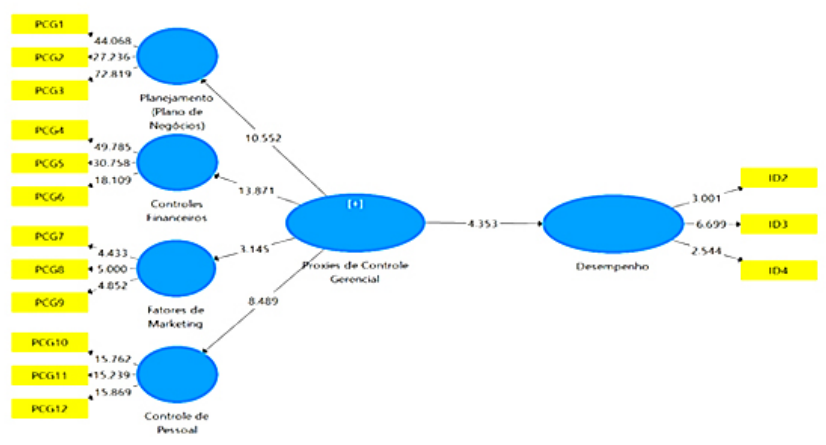

Relação entre proxies de controle gerencial e desempenho

Figura 5. Teste em modelos alternativos sem mediação.

Fonte: dados da pesquisa (2019).

A ilustração aponta que a relação direta entre características do empreendedor e desempenho demonstrou não ser significativamente correlacionada $(t=0.547)$. $\mathrm{Na}$ análise das outras duas relações (características do empreendedor $\mathrm{X}$ proxies de controle gerencial; proxies de controle gerencial $\mathrm{X}$ desempenho), ambas mostraram-se significativa a 5\%. O coeficiente de caminhos assinalou a influência de proxies no desempenho em $40,9 \%$ sem a presença de características empreendedoras. 
Com base nos quatro passos aprensentados por Hair Jr. et al. (2009), observa-se então que: a relação entre $V I$ e $V D$ altera-se quando $V M$ está presente, tornando-se significativa. Se ela permanecesse sem correlação direta, mas com correlação indireta, a mediação seria completa como apontado no quarto passo da Figura 4. Hair Jr. et al. (2016) mencionam que a classificação de mediação indireta de Zhao, Lynch e Chen (2010) é semelhante ao conceito de mediação completa de Baron e Kenny (1986). Já a mediação complementar e a mediação concorrente condizem com a mediação parcial, também segundo Baron e Kenny (1986).

Os coeficientes de caminhos entre os contrutos, no modelo completo, demonstram que o efeito direto da VI sobre a VD é negativo (- 0.364) e o efeito indireto é positivo (0.413), indicando uma mediação concorrente. Mediante esses resultados, é possível concluir que o construto proxies de controle gerencial atua como mediador parcial e concorrente na relação características do empreendedor e desempenho, uma vez que a presença dele na relação não apenas gera significância direta entre elas, como também produz um efeito maior e positivo, ainda que de forma indireta (Tabela 6).

Portanto, a fim de discutir os resultados do estudo, segue-se com a verificação das hipóteses levantadas, expostas na Figura 6 a seguir.

\begin{tabular}{llc}
\hline & \multicolumn{1}{c}{ Hipóteses } & Resultado \\
\hline H1 & As características do empreendedor influenciam positivamente o desempenho. & Rejeitada \\
\hline H2 & $\begin{array}{l}\text { As características do empreendedor influenciam positivamente o uso de proxies de } \\
\text { controle gerencial. }\end{array}$ & Não Rejeitada \\
\hline H3 & O uso de proxies de controle gerencial influencia positivamente o desempenho. & Não Rejeitada \\
\hline H4 & $\begin{array}{l}\text { As proxies de controle gerencial atuam como mediadoras positivas na relação } \\
\text { características do empreendedor e desempenho organizacional. }\end{array}$ & Não Rejeitada \\
\hline
\end{tabular}

Figura 6. Resultados das hipóteses da pesquisa

Fonte: os autores (2019)

Ao investigar a relação entre realização, planejamento, poder e desempenho, Lizote e Verdinelli (2014) encontraram uma relação significativa com desempenho de apenas seis das dez características trabalhadas no Empretec. Destas, "busca por oportunidades e iniciativa" e "exigência de qualidade e eficiência" relacionaram-se negativamente com o desempenho. Assim, a relação direta negativa entre características do empreendedor e desempenho dos empreendimentos, com a rejeição de H1, corroboram com alguns resultados encontrados em Lizote e Verdinelli (2014).

De outra forma, contrariam outros estudos como Fontenelle \& Hoeltgebaum (2006); Man, Lau \& Snape (2008); Veit \& Gonçalves Filho (2008); Eravia, Handayani \& Julina (2015); Lizote e Verdinelli (2015) Daciê et al. (2017). Essa rejeição de H1 está relacionada a uma presença significativa na amostra de características empreendedoras e um baixo desempenho (identificados pelas medidas de tendência central), evidenciando que outros fatores influenciam essa relação, como ponderado por Rauch et al. (2009) e Spillecke e Brettell (2013).

Como apontado por Herron e Robson Jr. (1993), alguns estudos obtiveram associações significativas entre os dois construtos, e em outros, não, advertindo ainda quanto à consideração das características do empreendedor, acima de qualquer outro fator sobre o sucesso de um empreendimento. Essas diferenças podem estar relacionadas às amostras pesquisadas e ao questionamento se de fato há uma uma personalidade sublime que se relacione com o desempenho (Gartner, 1989; Kerr, Kerr \& Xu, 2018).

Em referência a H2, H3 e H4, são resultados consonantes com Leite (2016) e Daciê et al. (2017), onde identificaram que características do empreendedor influenciam positivamente o uso de proxies de controle gerencial. Da mesma forma, essas proxies geram influência positiva sobre o desempenho e os controles gerenciais potencializam o efeito de características empreendedoras sobre o desempenho. 
Embora essas características do empreendedor (realização, planejamento e poder) não tenham apresentado relação direta positiva com o desempenho, demonstrou influência positiva por meio do uso de controles gerenciais, indicando sua contribuição para o desempenho organizacional (Bomfim \& Torkomian, 2017).

A explicação de $62,1 \%$ do desempenho por controles gerenciais reforçam a concepção de que estes são importantes para as micros e pequenas empresas (Santos, Dorow \& Beuren, 2016), indicando a necessidade de serem aplicadas com maior empenho e evidenciando que empreendedores precisam também atuar de forma objetiva (Fillion, 2000). A relação entre características do empreendedor e as proxies de controle gerencial coadunam com a menção em Roper (1998) de que controle e gestão tem substancial relação com essas características.

\section{Considerações Finais}

A relevância dos controles gerenciais para as organizações e o seu papel no desempenho delas são representados por uma linha homogênea na literatura. No entanto, a relação de características empreendedoras e o desempenho ainda trazem heterogeneidade de resultados em pesquisas que a investigaram, assim como é multifacetada a literatura que trata de empreendedorismo. Isso resulta em um questionamento se de fato essas características são valorosas aos empreendimentos.

O objetivo da contribuição empírica é mostrar a atuação das características empreendedoras (não trabalhadas até o momento pela assistência técnica) e sua relação com os demais construtos propostos, a fim de subsidiar o desenvolvimento para a atividade de piscicultura no Estado de Mato Grosso do Sul, onde a produção ainda sofre com muitos entraves. No entanto, a influência direta negativa de características do empreendedor no desempenho do negócio afloram questionamentos em torno de si.

A presente pesquisa confirmou que o uso de proxies de controle gerencial é também fator determinante ao desempenho de pisciculturas, assim como o é para empresas de outros setores da economia. Tal situação se deve ao fato de que essas proxies influenciam direta e positivamente o desempenho dessas organizações em $62,1 \%$, na presença de caraterísticas empreendedoras, e ainda atuam como mediadoras nessa relação.

A reespecificação do modelo, por meio da estratégia de desenvolvimento de modelos: excluiu a variável persistência, alocou a variável correr riscos calculados para a variável latente planejamento e excluiu o indicador de desempenho crescimento das vendas. Sugere-se a futuras pesquisas que esse novo modelo seja aplicado em outras amostras, como recomendado por Hair Jr. et al. (2009), aflorando ainda uma reflexão sobre o modelo de características empreendedoras utilizado no Empretec: haveria necessidade de reavê-lo?.

Dada a relação entre os construtos do modelo, recomenda-se que essas variáveis sejam trabalhadas com maior esforço em demais pisciculturas de pequeno porte, como é o caso da amostra pesquisada, sendo interessante ainda incluir outras variávies que possam explicar esse desempenho. Esse trabalho não explorou as questões qualitativas sobre essas interações. Trabalhos futuros poderiam investigar quais os motivos dessas características empreendedoras dos psicultores influenciarem negativamente o desempenho da atividade de piscicultura.

O estudo apresentou algumas limitações, como o tamanho da amostra e sua característica não probabilística e por conveniência, o que impossibilita generalizações. Outra limitação ocorre devido ao constructo características do empreendedor ser obtido por meio de um modelo preexistente, o Empretec, dessa forma não foram formuladas hipóteses e análises sobre os subconstructos realização, planejamento e poder. A tempo, foi fornecido um relatório simplificado da pesquisa para a empresa de assistência técnica. 


\section{Referências}

Ahmad, K., \& Zabri, S.M. (2015). Factors explaining the use of management accounting practices in Malaysian medium-sized firms. Journal of Small Business and Enterprise Development, 22(4), pp. 762-781. Doi: https://doi.org/10.1108/JSBED-04-2012-0057

Bomfim, E.M.C., \& Torkomian, A.L.V. (2017). Características empreendedoras associadas ao desempenho de micro, pequenas e médias EBTs do setor de TIC em Ribeirão Preto. GEPROS. Gestão da Produção, Operações e Sistemas, v. 12(4), pp. 128-158. Doi: https://doi.org/10.15675/gepros.v12i4.1751

Brito, R.P. de, \& Brito, L.A.L. (2012). Vantagem competitiva, criação de valor e seus efeitos sobre o desempenho. Revista de Administração de Empresas, 52(1), pp.70-84. Doi: https://doi.org/10.1590/ S0034-75902012000100006

Brush, C.G., Vanderwerf, P.A. (1992). A comparison methods and sources for obtaining estimates of new venture performance. Journal of Business Venturing, 7 (2), pp. 157-170. Doi: https://doi. org/10.1016/0883-9026(92)90010-O

Carland, J.W., Hoy, F., Boulton, W.R., Carland, J.C. (1984). Differentiating Entrepreneurs from Small Business Owners: A Conceptualization. The Academy of Management Review, 9(2), pp. 354-359. Doi: https://doi.org/10.2307/258448

Carland, J.C., \& Carland, J.W. (1996). The theoritetical bases and dimensionality of the Carland Entrepreneurship Index. Presented to the RISE conference, and published in the Proceedings of the RISE ' 96 Conference, University of Jyväskylä, Finland, pp 1-24.

Chandler, G.N., \& Jansen, E. (1992). The founder's self-assessed competence and venture performance. Journal of Business Venturing, 7 (3), pp. 223-236. Doi: https://doi.org/10.1016/0883-9026(92)90028-P

Chandler, G.N. \& Hanks, S.H. (1993). Measuring the performance of emerging business: a validation study. Journal of Business Venturing, 8 (5), pp. 391-408. Doi: https://doi.org/10.1016/08839026(93)90021-V

Chenhall, R.H. (2003). Management control systems design within its organizational context: findings from contingency-based research and directions for the future. Accounting Organizations and Society, 28 (2-3), pp. 127-168. Doi: https://doi.org/10.1016/S0361-3682(01)00027-7

Cohen, J. (1988) Statistical Power Analysis for the Behavioral Sciences. (2a ed.) New York: Psychology Press.

Cooper, A. (2003). Entrepreneurship: the past, the present, the future. Handbook of Entrepreneurship Research, pp. 21-34. Doi: https://doi.org/10.1007/0-387-24519-7_2

Cooper, D.R., \& Schindler, P.S. (2016). Métodos de Pesquisa em Administração. (12a. ed.) Porto Alegre: Bookman.

Crotty, M. (1998). The Foundations of Social Research: Meaning and Perspective in the Research Process. London: SAGE publications.

Daciê, F. do P. (2016). Os iguais se diferem? Características determinantes do uso de proxies de controle gerencial em empresas do ambiente institucional APL de confecção.. Dissertação de Mestrado em Ciências Contábeis, Universidade Federal do Paraná. Recuperado de https://acervodigital.ufpr.br/ handle/1884/42716

Daciê, F. do P., Espejo, M.M. dos S.B., Gimenez, F.A.P., \& Camacho, R.R. (2017). Are similar ones different? Determinant characteristics of management toolusage within companies sharing the same institutional environment. Rausp Management Journal, 52 (3), pp. 341-352. Doi: http://dx.doi. org/10.1016/j.rausp.2017.05.006 
Eggers, K. F., Guth, S. C., da Motta, M. E. V., Camargo, M. E., Fernandes, A. M., Prusch, R. V. F., \& Tondolo, V. A. G. (2016). Empresa rural de piscicultura: criação de tilápias. Custos e agronegócio online, 12(4), pp. 295-309. Recuperado de http://www.custoseagronegocioonline.com.br/numero4v12/OK\%20 $14 \% 20$ tilapia.pdf

Eravia, D., Handayani, T., \& Julina. (2015). The opportunities and Threats of small and médium enterprises in Pekanbaru: comparison between SMEs in food and restaurant industries. Procedia Social and Behavioral Sciences, 169 (20), pp. 88-97. Doi: http://dx.doi.org/10.1016/j.sbspro.2015.01.289

Fillion, L.J. (1999). Empreendedorismo: empreendedores e proprietários-gerentes de pequenos negócios. Tradução de Maria Letícia Galizzi e Paulo Luz Moreira. Revista de Administração, 34(2), pp. 5-28. Recuperado de https://www.academia.edu/1168821/Empreendedorismo_empreendedores_e_ propriet\%C3\%A1rios_gerentes_de_pequenos_neg\%C3\%B3cios

Fillion, L.J. (2000). Empreendedorismo e gerenciamento: processos distintos, porém complementares. Revista de Administração de Empresas, 7(3), pp. 2-7. Recuperado de https://www.scielo.br/pdf/ rae/v40n3/v40n3a13.pdf

Furtado, J. F. R. (1995). Piscicultura: uma alternativa rentável. Guaíba, RS: Agropecuária.

Fontenelle, C.J.S., \& Hoeltgebaum, M. (2006). A influência do perfil empreendedor no desempenho do negócio em um rede de franquia de confecção infantil. Revista de Negócios, 11(4), pp.131-149. Doi: http://dx.doi.org/10.7867/1980-4431.2006v11n4p131-149

Frezatti, F., Carter, D.B., \& Barroso, M.F.G. (2014). Accounting without accounting: Informational proxies and the construction of organisational discourses. Accounting, Auditing \& Accountability Journal, 27(3), pp. 426-464. Doi: http://dx.doi.org/10.1108/AAAJ-01-2012-00927

Galli, L. F., \& Torloni, C. E. C. (1999). Criação de peixes. São Paulo: Nobel.

Garg, A.K., Joubert, R.J.O., \& Pellissier, R. (2004). Measuring business performance: a case study. Southern African Business Review,.8(1), pp.7-21. Recuperado de https://hdl.handle.net/10520/EJC91239

Gartner, W.B. (1989) “Who is an entrepreneur?" Is the wrong question. Entrepreneurship Theory and Practice, v. 13(2), pp. 47-68. Doi: http://dx.doi.org/10.1177/104225878801200401

Gil, A.C. (2002). Como elaborar projetos de pesquisa. (4a ed.) São Paulo: Atlas.

Govindarajan, V. (1984).Appropriateness of accounting data in performance evaluation: na empirical examination of environmental uncertainty as an intervening variable. Accounting Organizations and Society, 9(2), pp. 125-135. Doi: https://doi.org/10.1016/0361-3682(84)90002-3

Grégoire, D.A., Noel, M.X., Déry, R., \& Béchard, J.-P. (2006). Is There Conceptual Convergence in Entrepreneurship Research? A Co-Citation Analysis of Frontiers of Entrepreneurship Research, 1981-2004. Entrepreneurship Theory and Practice, v. 30(3), p. 333-373. Doi: https://doi.org/10.1111/ j.1540-6520.2006.00124.x

Hair Jr., J.F., Black, W.C., Babin, B.J., Anderson, R.E., \& Tatham, R.L. (2009). Análise multivariada de dados. (6a ed.) Porto Alegre: Bookman.

Hair Jr., J.F., Hult, D.G.T.M., Ringle, C.M., \& Sarstedt, M. (2016). A primer on partial least squares structural equation modeling (PLS-SEM). (2a ed.) SAGE publications.

Hartman, H. (1954). Managers and entrepreneurs: a useful distinction?. Administrative Science Quaterly, 3 (4) pp. 429-451. Doi: https://doi.org/10.2307/2390809

Herron, L., \& Robinson Jr., R.B. (1993). A structural model of the effects of entrepreneurial characteristics on venture performance. Journal of Business Venturing, 8 (3), pp. 281-294. https://doi. org/10.1016/0883-9026(93)90032-Z 
Hopwood, A.G. (1972). The relationship between accounting and personnel management - past conflicts and future potential. Personnel Review, 1(2), pp. 40-47. Doi: https://doi.org/10.1108/eb055199

IPEA. (2017). Evolução da Piscicultura no Brasil: diagnóstico e desenvolvimento da cadeia produtiva da Tilápia. Recuperado de http://repositorio.ipea.gov.br/bitstream/11058/8043/1/td_2328.pdf Junqueira, E., Dutra, E.V., Zanquetto Filho, H., \& Gonzaga, R.P. (2016). O efeito das escolhas estratégicas e dos sistemas de controle gerencial no desempenho organizacional. Revista Contabilidade \& Finanças, 27(72), pp. 334-348. Doi: https://doi.org/10.1590/1808-057x201601890

Kallunki, J.P., Laitinen, E.K., \& Silvola, H. (2011). Impact of enterprise resource planning systems on management control systems and firm performance. International Journal of Accounting Information Systems, 12 (1), pp. 20-39. Doi: https://doi.org/10.1016/j.accinf.2010.02.001

Kerr, S.P., Kerr, W.R., \& Xu, T. (2018). Personality traits of entrepreneurs: a review of recent literature. Harvard Business School Working Paper, No. 18-047. Recuperado de https://www.hbs.edu/faculty/ Pages/item.aspx?num $=53601$.

Leite, H. de O. (2016). Desempenho de micro e pequenas empresas: um estudo a luz das características do empreendedor-gestor e do controle gerencial. Dissertação de Mestrado, Universidade Federal do Paraná, Curitiba, PR, Brasil. Recuperado de https://acervodigital.ufpr.br/bitstream/ handle/1884/42435/R\%20-\%20D\%20-\%20HELENA\%20DE\%20OLIVEIRA\%20LEITE\%20 FEUSER.pdf?sequence $=1$

Lenzi, F. C. (2008). Os empreendedores corporativos nas empresas de grande porte dos setores mecânico, metalúrgico e de material elétrico/comunicação em Santa Catarina: um estudo da associação entre os tipos psicológicos e competências empreendedoras reconhecidas. Tese de Doutorado, Universidade de São Paulo, São Paulo, SP, Brasil. Doi: https://doi.org/10.11606/T.12.2008.tde-15012009-105920

Lima, E.M., Espejo, M.M. dos S.B., Pereira, C.A., \& Frezatti, F. (2011). As respostas do GECON às críticas do Relevance Lost. Revista Contabilidade Vista \& Revista,22(1), pp. 177-200. Recuperado de https:// revistas.face.ufmg.br/index.php/contabilidadevistaerevista/article/view/832

Lizote, S.A., \& Verdinelli, M.A. (2014). Relação entre competências empreendedoras e desempenho: um estudo em empresas prestadoras de serviços contábeis. Revista de Contabilidade e Organizações, 8(22), pp. 49-59. Doi: https://doi.org/10.11606/rco.v8i22.55605

Lizote, S.A., \& Verdinelli, M.A. (2015). Relação entre competências empreendedoras e desempenho: um estudo em meios de hospedagem do ambiente rural. Desenvolvimento em Questão, 13(29), pp. 90124. Doi: https://doi.org/10.21527/2237-6453.2015.29.90-124

Lobontiu, G., \& Lobontiu, M. (2014). The owner-manager and the functional management of a small firm. Procedia Social and Behavioral Sciences, 124(20), pp. 552-561. Doi: https://doi.org/10.1016/j. sbspro.2014.02.519

Low, M.B., \& Macmillan, I.C. (1988). Entrepreneurship: past research and future challenges. Journal of Management, 14(2), pp. 139-161. DOIDoi: https://doi.org/10.1177/014920638801400202

Macinati, M.S., \& Anessi-Pessina, E. (2014). Management accounting use and financial performance in public health-care organisations: evidence from the Italian National health servisse. Health Policy, 117(1), pp. 98-111. Doi: https://doi.org/10.1016/j.healthpol.2014.03.011

Malmi, T., \& Brown, D.A., (2008). Management control Systems as a package - Opportunities, challenges and research directions. Management Accounting Research, vol.19(4) , p. 287-300. Doi: https://doi. org/10.1016/j.mar.2008.09.003 
Man, T.W.Y., Lau, T., \& Chan, K.F. (2002). The competitiveness of small and medium enterprises: conceptualization with focus on entrepreneurial competencies. Journal of Business Venturing, 17 (2), pp. 123-142. Doi: https://doi.org/10.1016/S0883-9026(00)00058-6

Man, T.W.Y., Lau, T., \& Snape, E. (2008). Entrepreneurial competencies and the performance of Small and Medium Enterprises: an investigation through a framework of competitiveness. Journal of Small Business and Entrepreneurship, 21(3), pp. 257-276. Doi: https://doi.org/10.1080/08276331.2008.1 0593424

Martins, G. de A., \& Theophilo, C.R. (2016). Metodologia da investigação científica para ciências sociais aplicadas. (3a. ed.) São Paulo: Atlas.

Masakure, O., Cranfield, J., \& Henson, S. (2008). The financial performance of non-farm microenterprises in Gana. World Development,36(12), pp. 2733-2762. Doi: https://doi.org/10.1016/j. worlddev.2007.12.005

Maziriri, E.T., \& Mapuranga, M. (2017). The impact of management accounting practices (Maps) on the business performance of small and medium enterprises within the gauteng province of South Africa. Journal of Accounting and Management,.7(2). Recuperado de http://journals.univ-danubius. ro/index.php/jam/article/view/4018/4183

McClelland, David C. (1972). A sociedade competitiva: realização e progresso social. Rio de Janeiro: Expressão e Cultura.

McClelland, David C. (1987). Characteristics of successful entrepreneurs. The Journal of Creative Behavior, Buffalo, 21(3), pp. 219-233. Doi: https://doi.org/10.1002/j.2162-6057.1987.tb00479.x

Merchant, K.A., \& Van der Stede, W.A. (2003). Management control systems, Edinburgh Gate: Pearson Education.

Mia, L., \& Chenhall, R.H. (1994). The usefulness of management accounting systems, functional differentiation and managerial effectiveness. Accounting Organizations and Society, 19(1), pp. 1-13. https://doi.org/10.1016/0361-3682(94)90010-8

Mingoti, S.A. (2005). Análise de dados através de métodos de estatística multivariada: uma abordagem aplicada. Belo Horizonte: Editora UFMG.

Mitchell, F., \& Reid, G.C. (2000). Editorial. Problems, challenges and opportunities: the small business as a setting for management accounting research. Management Accounting Research, 11(4), pp. 385390. Doi: https://doi.org/10.1006/mare.2000.0152

Mitchelmore, S., \& Rowley, J. (2010). Entrepreneurial competencies: a literature review and development agenda. International Journal of Entrepreneurial Behavior \& Research, 16(2), pp. 92-111. Doi: https:// doi.org/10.1108/13552551011026995

Mizumoto, F.M., Artes, R., Lazzarini, S.G., Hashimoto, M., \& Bedê, M.A. (2010). A sobrevivência de empresas nascentes no estado de São Paulo: um estudo sobre capital humano, capital social e práticas gerenciais. Revista de Administração. São Paulo, 45(4), pp. 343-355. Doi: https://doi.org/10.1016/ S0080-2107(16)30466-6

Murphy, G.B., Trailer, J.W., \& Hill, R.C. (1996). Measuring performance in entrepreneurship research. Journal of Business Research, 36 (1), pp. 15-23. https://doi.org/10.1016/0148-2963(95)00159-X

Nascimento, J.C.H.B. do, \& Macedo, M.A. da S. (2016). Modelagem de equações estruturais com mínimos quadrados parciais: um exemplo de aplicação do SmartPLS em pesquisas em contabilidade. REPEC, 10(3), pp. 289-313. Doi: https://doi.org/10.17524/repec.v10i3.1376

Obschonka, M., \& Stuetzer, M. (2017). Integrating psychological approaches to entrepreneurship: the Entrepreneurial Personality System (EPS). Small Business Economics, 49, pp. 203-231Doi: https:// doi.org/10.1007/s11187-016-9821-y 
Oyadomari, J.C.T., Frezatti, F., Mendonça Neto, O.R. de, Cardoso, R.L., \& Bido, D. de S. (2011). Uso do sistema de controle gerencial e desempenho: um estudo em empresas brasileiras sob a perspectiva da resources-based view. Revista Eletrônica de Administração, 17(2), pp. 298-329. Recuperado de https://seer.ufrgs.br/read/article/view/38527/24749

Otley, David. (1978). Budget use and managerial performance. Journal of Accounting Research, 16(1) pp 122-149. Doi: https://doi.org/10.2307/2490414

Otley, David. (1994). Management Control in contemporany organizations: towards a wider framework. Management Accounting Research, 5(3-4), pp. 289-299. https://doi.org/10.1006/mare.1994.1018

Padoveze, C.L. (1999). O papel da contabilidade gerencial no processo empresarial de criação de valor. Cadernos de Estudo USP, 21. DoiI: https://doi.org/10.1590/S1413-92511999000200003

Peake, W., \& Marshall, M.I. (2017). Women's management practices and performance in rural femaleowned family businesses. Journal of Family Business Management, 7(2), pp.134-150. Doi: https:// doi.org/10.1108/JFBM-06-2016-0012

Raifur, L. (2013). Fatores determinantes de desempenho de pequenas e médias empresas da região centrosul do estado do Paraná. Tese de Doutorado, Universidade de São Paulo, São Paulo, SP, Brasil. Doi: https://doi.org/10.11606/T.12.2013.tde-13032014-164618

Rauch, A., Wiklund, J., Lumpkin, G.T., \& Frese, M. (2009). Entrepreneurial orientation and business performance: an assessment of past research and suggestions for the future. Entrepreneurship Theory and Practice, 33(9), pp. 761-787. Doi: https://doi.org/10.1111/j.1540-6520.2009.00308.x

Reid, G., Smith, J. (2002). Feature information management systems. Financial Management, pp.24-26. Recuperado de https://pureportal.strath.ac.uk/en/publications/the-bigger-picture-feature-oninformation-management-systems

Richard, P.J., Devinney, T.M., Yip, G.S., \& JOHNSON, G. (2009). Measuring organizational performance: towards methodological best practice. Journal of Management, 35(3). Doi: https://doi. org/10.1177/0149206308330560

Ringle, C.M., Silva, D. da, \& Bido, D. (2014). Modelagem de equações estruturais com utilização do SmartPLS. Revista Brasileira de Marketing, 13(2), pp. 54-71. Doi: https://doi.org/ 10.5585/remark. v13i2.2717

Roper, S. (1998). Entrepreneurial Characterístics, strategic, choice and small business performance. Small Business Economics, 11, pp. 11-24. Recuperado de https://www.academia.edu/3230210/ Entrepreneurial_Characteristics_Strategic_Choice_and_Small_Business_Performance

Santos, V. dos, Dorow, D.R., \& Beuren, I.M. (2016). Práticas gerenciais de micro e pequenas empresas. Revista Ambiente Contábil, 8(1), pp. 153-186. Recuperado de https://periodicos.ufrn.br/ambiente/ article/view/7271/6032

Silva, M.A.O.M. da, Gomes, L.F.A.M., \& Correia, M.F. (2009). Cultura e orientação empreendedora: uma pesquisa comparativa entre empreendedores em incubadoras no Brasil e em Portugal. Revista de Administração Contemporânea, 13(1), pp. 57-71. https://doi.org/10.1590/S1415-65552009000100005

Spillecke, S.B., \& Brettel, M. (2013). The impact of sales management controls on the entrepreneurial orientation of the sales department. European Management Journal, 31(4), pp. 410-422. Doi: https:// doi.org/10.1016/j.emj.2012.07.002

Tomei, P.A., \& Souza, D.A.A.L.A. (2014). Análise das barreiras que dificultam a transformação do agricultor familiar em empreendedor rural no contexto brasileiro. Revista Ibero-Americana de Estratégia, 13(3), pp.107-122. Doi: https://doi.org/10.5585/riae.v13i3.2073 
Veit, M.R., \& Gonçalves Filho, C. (2008). O perfil do potencial empreendedor e seu impacto na gestão dos pequenos negócios. Rev. Ciênc. Admin., Fortaleza, 14(2), pp. 324-337. Recuperado de http:// hp.unifor.br/pdfs_notitia/2501.pdf

Venkatraman, N., \& Ramanujam, V. (1986). Measurement of business performance in strategy research: a comparison of approaches. The Academy of Management Review, 11(4), pp. 801-814. Doi: https:// doi.org 10.5465/AMR.1986.4283976

Zampier, M.A., \& Takahashi, A.R.W. (2011). Competências empreendedoras e processos de aprendizagem empreendedora: modelo conceitual de pesquisa. Ebape, 9, (ed. esp.), pp.564-585. https://doi. org/10.1590/S1679-39512011000600007

Wiklund, J. (1999). The sustainability of the entrepreneurial orientation-performance relationship. Entrepreneurship Theory and Practice,24(1), pp. 37-48. https://doi.org/10.1177\% 2F104225879902400103 